\title{
Navigating social-ecological trade-offs in small-scale fisheries management: an agent-based population model of stoplight parrotfish (Sparisoma viride) for a Caribbean coral reef fishery
}

\author{
Tyler Pavlowich $^{1}$, Anne R. Kapuscinski $^{2}{ }^{2}$ and D. G. Webster ${ }^{3}$
}

ABSTRACT. Parrotfish (family Scaridae) consume macroalgae, an essential process for sustaining the ecological health of coral reefs. They have become fisheries targets in several Caribbean locations, a practice that provisions food and income but also puts reefs at risk. Some countries have banned parrotfish harvest, but this would inflict substantial hardship for resource-poor fishers in some places, given the high proportion of parrotfish species in their catches. This research informs development and assessment of options for achieving the greatest level of population rebuilding with the least hardship imposed on fishers. Fishery models can help compare management options in the absence of real-world examples of how to manage parrotfish populations. We built an agent-based population model for the stoplight parrotfish (Sparisoma viride), a key herbivore and protogynous hermaphrodite, to predict ecological and social outcomes of various fishery management options. We parameterized the model to represent a heavily fished fishery, the context for which assessing different management options is most pertinent. We compared several management options selected through discussions with stakeholders and the scientific literature on fisheries management. We found that all options immediately began to increase population biomass. The more restrictive options led to greater increases in steady-state biomass and revenue from catch, representing a long-term win-win. However, all management options also caused an initial decrease in monetary value of the catch before the eventual rebound, hence a temporal trade-off between short- and long-term economic outcomes. Although there is no perfect strategy, managers and stakeholders can use this information to weigh the costs and benefits of different possible management options in different socialecological contexts.

Key Words: agent-based model; coral reef fisheries; fisheries management; parrotfish; Sparisoma viride

\section{INTRODUCTION}

Coral reefs provide coastal communities with multiple, highly valuable ecosystem services, but managing them to sustain these ecosystem services presents complex challenges. They sustain fisheries, provide opportunities for tourism, and protect coastlines (Moberg and Folke 1999). Fishing on coral reefs, however, has altered the structure of fish communities and, therefore, the way these ecosystems function (Dulvy et al. 2004, Graham et al. 2005, Madin et al. 2010). A key ecological dynamic is the way herbivorous fish and urchins keep algae at bay and allow corals to grow and reproduce by mediating competition between coral and macroalgae (Hughes 1994, Mumby et al. 2006). Fishing can remove herbivore abundance and alter community structure, putting reefs at risk of becoming overgrown with algae, losing the biodiversity that defines their structure and function, and failing to provide the same benefits to society that they would otherwise offer. Therefore, maintaining sufficient levels of herbivory is a cornerstone of sustainable reef fisheries management (Nyström et al. 2008, McClanahan et al. 2012).

A key social factor is that herbivorous parrotfish (family Scaridae) can make up a large portion of fishers' catch (Sabetian 2010, Pavlowich and Kapuscinski 2017), posing a real challenge for regulating parrotfish harvest without causing undesirable disruption to fishers' livelihoods. Complete bans on parrotfish capture within Caribbean fisheries have been advocated for (Bellwood et al. 2004, Jackson et al. 2012, Rogers et al. 2015) to maximize chances of keeping these ecosystems in a coral- dominated state (Mumby 2006, Bozec et al. 2016). However, a complete ban would also cause enough economic hardship to make this approach socially untenable in many Caribbean coastal communities whose residents have few other viable livelihood options (Cinner 2011, Wilson et al. 2016). In the Dominican Republic, where the empirical portion of our study took place, a 2-year ban on parrotfish was put in place in June 2017 (Ministerio de Medio Ambiente y Recursos Naturales 2017). Artisanal fishers in the Dominican Republic have reported steep reductions in total catch since implementation of the parrotfish ban (T. Pavlowich, personal observation).

Bozec et al. (2016) created a demographic model of Caribbean parrotfish and coral reef dynamics to find the level of parrotfish extraction the ecosystem can sustain without collapsing into an algae-dominated state. Their model is based heavily on extensive population and life history data of stoplight parrotfish (Sparisoma viride) in the unfished reefs of Bonaire (van Rooij et al. 1996a, $b$ ). They examined fishery ecosystem dynamics with a very broad scope, from fishing to herbivore population dynamics to coral accretion rates. They found that protecting reefs requires low fishing mortality on parrotfish, and that prohibiting use of fish traps achieves adequate protection of these species and herbivory. Their work provides an important step toward understanding the way fishing affects reef ecosystems and how it can be managed to maintain ecological resilience.

Our goal was to advance this line of research by exploring the performance of other management options in other ecological

\footnotetext{
${ }^{1}$ Integrated Statistics, ${ }^{2}$ Coastal Science and Policy Program \& Environmental Studies Department, University of California, Santa Cruz,

${ }^{3}$ Environmental Studies Program, Dartmouth College
} 
contexts, because we know that resource management will necessarily vary on a case-by-case basis (Ostrom 2007). Our three research objectives, under this goal, were the following:

1. Describe the parrotfish population and fishing practices in a heavily fished Caribbean coral reef.

2. Create a population model for parrotfish that functions like an overexploited reef under current fishing conditions.

3. Predict and compare the short- and long-term ecological and economic results of implementing many different potential fishery management regulations.

To meet the first objective, we studied the fish community and artisanal fishing practices of a fishery ecosystem in the Dominican Republic. To achieve the second objective, we modified a model that we had created earlier, which was in turn based on previously published parrotfish models (Bozec et al. 2016). We focused the scope of our research on fishing and population dynamics of a single parrotfish species so that we could explore a greater number of alternative regulatory options (Weijerman et al. 2015). To meet the final objective, we used this model to predict and compare the effects of seven alternative fishery regulations, including the novel proposal of harvesting only terminal-phase male fish. We devised two aspects of our analysis of the impacts of regulation to make this research directly applicable to small-scale fisheries in highly dependent fishing communities. First, we included the fishers' income as a primary dimension of comparison. Second, we explored how stoplight parrotfish populations and fishers' income changed after implementing a given regulation, starting from the current situation, through the immediate disturbance, and until new equilibria were determined. This approach acknowledges the importance of financial impacts on fishers' daily lives when attempting to establish sustainable fishery systems.

\section{METHODS}

We used a previously developed agent-based model for stoplight parrotfish (Sparisoma viride) populations (Pavlowich et al. 2018) as the foundation for our study. The model builds on previous models used to explore the effects of fishing on hermaphroditic fish populations and the dynamics of stoplight parrotfish populations (Alonzo and Mangel 2004a, b, O'Farrell et al. 2015, Bozec et al. 2016). We parameterized the model for stoplight parrotfish in a heavily fished artisanal fishery, using data collected in Buen Hombre, Dominican Republic. We follow the standard protocol for describing agent-based models, i.e., overview, design concepts, and details, throughout the Methods (Grimm et al. 2010).

\section{Empirical data collection}

We assessed the current state of local fish populations in Buen Hombre by using underwater visual census techniques to conduct fish community surveys (McClanahan et al. 2007, Lang et al. 2010). We performed the surveys with transects that were $30 \mathrm{~m}$ long and $4 \mathrm{~m}$ wide in reef habitat of all depths $(1-25 \mathrm{~m})$ throughout the Buen Hombre fishery area. Transect locations were chosen randomly within larger sampling areas chosen intentionally to achieve representative coverage of the diversity of habitats and fishing locations. Surveys were stratified within 3 habitat divisions based on depth: 0-3 m, 3-8 m, and 8-25 m. We conducted 66 transects in reef habitats in 2013 and 47 transects in 2014. When summarizing these data, we corrected for disproportional sampling effort among reef habitat types relative to the area each habitat type occupies. We found the length frequencies of fish within each habitat type, multiplied each frequency by the ratio of the areal proportion of a given habitat type to the proportion of that habitat type that occurred in our sampling each year, and then summed the length frequencies of all habitat types. For example, fish observed in deep reef areas counted as 2.77 fish in the 2013 samples and 2.40 fish in the 2014 samples, whereas each fish observed in shallow water counted as 0.19 fish in 2013 and 0.21 fish in 2014 (Table 1). We aggregated fish into 5-cm bins to match the data reported in other stoplight parrotfish population studies (van Rooij et al. 1996a, O'Farrell et al. 2015). We calculated and plotted the mean adjusted length frequencies for each $5-\mathrm{cm}$ size class for each year and then plotted the overall mean $(n=2)$, the lower mean value, and the higher mean value (Fig. 1, lower panel). We calculated the sex ratio as the ratio of initial-phase fish to terminal-phase fish observed in 2014, the only year we collected data on individuals' life phase. These data were adjusted as described previously to account for survey stratification, and all fish less than $15 \mathrm{~cm}$ were assumed to be immature, neither initialnor terminal-phase regardless of coloration.

Table 1. Fish community sampling was not proportional to the area of each depth category, and thus numbers at length were corrected to derive a whole-fishery estimate of population structure.

\begin{tabular}{lccccc}
\hline \hline $\begin{array}{l}\text { Reef } \\
\text { Depth }\end{array}$ & \multicolumn{2}{c}{$\begin{array}{c}\text { Sites Sampled } \\
\text { (Proportion) }\end{array}$} & $\begin{array}{c}\text { Proportion } \\
\text { of } \\
\text { Fishery } \\
\text { Area }\end{array}$ & & \multicolumn{2}{c}{ Multiplier } \\
\cline { 2 - 3 } & 2013 & 2014 & & 2013 & 2014 \\
\hline$<3 \mathrm{~m}$ & $42(0.64)$ & $27(0.57)$ & 0.12 & 0.19 & 0.21 \\
$3-8 \mathrm{~m}$ & $7(0.11)$ & $6(0.13)$ & 0.16 & 1.45 & 1.23 \\
$8-25 \mathrm{~m}$ & $17(0.26)$ & $14(0.30)$ & 0.72 & 2.77 & 2.40 \\
\hline
\end{tabular}

We also collected species and size data on fishers' daily catch and used these data to model fishers' size selectivity. This involved identifying the species and measuring the fork length of every fish a fisher caught in a day. We recorded 16 instances of daily catch from 10 different spearfishers in 2014. The only opportunity to collect these data without disrupting fishers' normal activities was on the boat ride back from the day's fishing area to the landing point. This sampling was therefore not random but based on convenience. We purposefully sought catch data from as many different fishers as possible. In Buen Hombre, spearfishers practice both free diving and compressor diving. We were unable to measure catch from compressor divers because of the logistical constraints of accompanying these fishers. Previous research on spearfishing in Buen Hombre suggests that compressor divers usually access deeper areas with more and sometimes larger fish. However, both types of fishers operate in the same market environment, and compressor divers catch the same types of fish, though perhaps more of them, as free divers (Pavlowich and Kapuscinski 2017). 
Fig. 1. The size distributions of stoplight parrotfish (Sparisoma viride) in Bonaire (top) and Buen Hombre (middle) were nearly opposite one another. Bars in both distributions show the mean fish density, weighted by the proportion of habitat type in which fish were sampled. The error bars in the Bonaire data are $95 \%$ confidence intervals, whereas the error bars in the Buen Hombre data are the minimum and maximum values from 2 years of sampling. The simulated population structure under the status quo fishing scenario (bottom) when parameterized to the Buen Hombre fishery accurately reproduced key characteristics of the observed population. Size frequencies for the simulated population are the mean ending values from 3 runs, and error bars are standard errors.

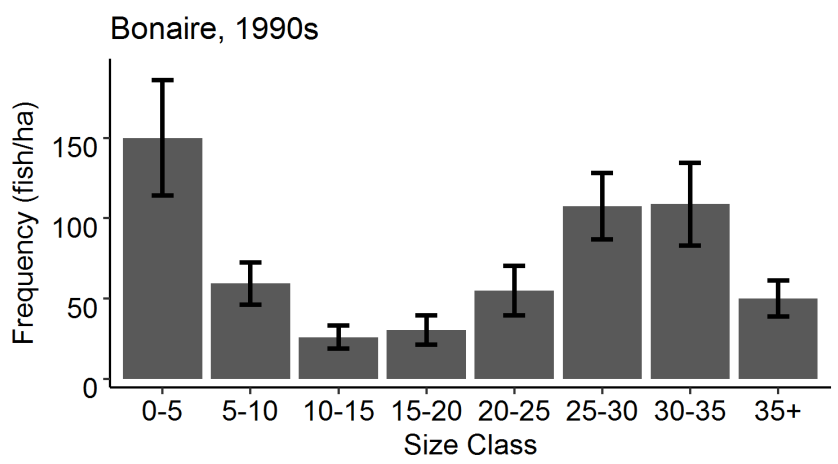

Buen Hombre, 2013-2014
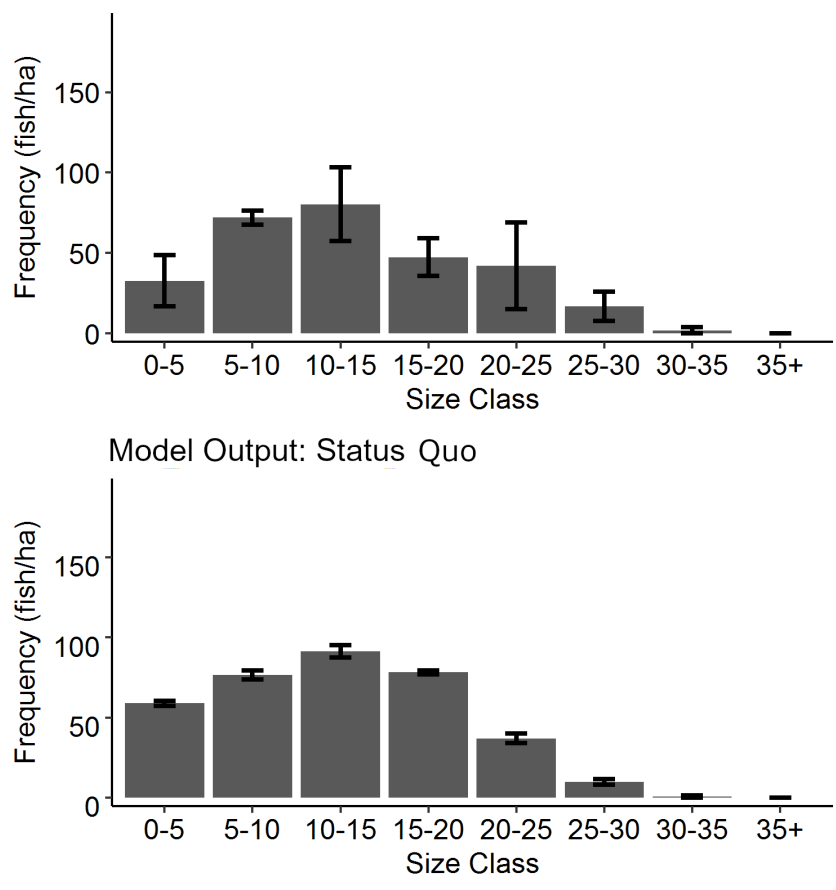

To estimate fishers' income, we assigned fish monetary value the same way fish buyers do in Buen Hombre. The price per weight paid for fish is determined by a fish's size and species (Pavlowich and Kapuscinski 2017). The same size classification holds for all species, but certain species can enter into more valuable price categories than others. Parrotfish, for example, can be either "third class," which is the least valuable (RD\$37; Dominican pesos in 2014), or "second class," which is worth more than third class and less than first class (RD\$52). Individuals larger than 20$\mathrm{cm}$ fork length are considered second class, and anything smaller is third class. There is no official lower size limit, though very small fish $(\sim 15 \mathrm{~cm})$ are discouraged and sometimes refused by buyers in Buen Hombre. We express the price in terms of Dominican pesos per kilogram.

\section{Overview}

Purpose

The purpose of the model is to explore and compare the effects of various fishery regulations on population metrics and catch characteristics of stoplight parrotfish within the context of a heavily fished fishery ecosystem. The foci of the analysis are the magnitude of population rebuilding from an overexploited condition and the short- and long-term impacts on fishers' income from this species.

State variables and scales

The model has one hierarchical level: individual fish. Individuals are described by the state variables: identity number, fork length, weight, age, and life phase. Life-phase levels are juvenile, initial phase, transitional phase, and terminal phase. Initial-phase fish are assumed to be female, and terminal-phase fish male.

There is no spatial component to the model, other than that it represents 1 ha of reef. We create the context of a heavily fished fishery ecosystem by adjusting the model modules that represent various aspects of life history.

The population is characterized by the number of individuals in total, in each life phase, and within different size classes; sex ratio (female:male); biomass of all fish and fish of each life phase; mean length of mature fish; and spawning potential ratio (SPR; female biomass/female biomass when $F=0$ ). Catch is described by the number of fish caught at each time step, the weight of fish caught, and the market value of fish caught.

\section{Process overview and scheduling}

The model operates in weekly time steps. Within each time step, five modules are processed in the following order: growth, lifephase transition, maturation, mortality, and recruitment. All individuals, in a random order, process a module and then move on to the next module in a random order. The order of operations matters for some of the processes and not for others. Life-phase transitions and maturation must occur after growth, because the transitions are based on body size. If growth came after life-phase transition or maturation, some fish would have the incorrect life phase for their body size. Mortality and recruitment could occur either before or after growth and life-phase transition and produce the same results.

\section{Design concepts}

Emergence: Population dynamics, i.e., changes in population size and length and life-phase distributions, emerge from the combination of larval recruitment, somatic growth, life-phase transitions, and mortality. Fishing mortality is an especially important factor because it imposes variable mortality rates on fish of different sizes and life phases.

Sensing: Fish can sense their own size and life phase, as well as the size of all other mature fish in the population. We do not know the mechanism for this. Assessment could come via visual cues; 
physical interactions with other fish, such as chasing, nipping, and so forth; or both (Barlow 1975, Munday et al. 2006). A fish's size and life phase relative to the rest of the population influences an individual's life-phase transitions and susceptibility to fishing.

Interactions: Life-phase transitions are based on an individual's size relative to others in its social group. The precise mechanisms that determine which fish change life phase and when are not known for this species, but it is thought to involve size-based social hierarchies and to be established and maintained by interactions among fish.

Stochasticity: The model represents life-phase transitions, movement, and mortality as probabilities, which are therefore stochastic. The processes of growth and recruitment are deterministic.

Observation: We observed model outcomes at the population level, which includes the distribution of fish within subpopulation-level groups.

\section{Details}

\section{Initialization}

We began simulations with a population of 10 juveniles, 10 initialphase fish, and 10 terminal-phase fish. We set fishing parameters tuned to fishing in Buen Hombre (see further explanation in Details: Parameter estimation) and allowed the model to run until population biomass and fishers' income stabilized ( 3 years or 156 weeks). We then recorded characteristics of the population and catch for the following 2 years (104 weeks) to represent the "before" status prior to applying one of the fishing regulations.

\section{Submodels}

Submodels of life history processes form the skeleton of this population model. The formulas for these processes were chosen from the best available information. For some, the literature provides a good understanding of the process in general and for stoplight parrotfish specifically. For others, we had to use simple formulations and estimate parameter values. In the parameterization procedure, described after the submodel descriptions, having good information on some processes and population characteristics constrained the possible parameter values that could lead to expected outcomes, enhancing our confidence in the estimates.

\section{(i) Reproduction}

The model assumes constant larval recruitment, i.e., there is no stock-recruitment function. Coral reef scientists often make this assumption in fish population models (Kellner et al. 2010, O'Farrell et al. 2015), even though recruitment varies temporally (Tolimieri 1998, Sponaugle et al. 2006) and is likely to be at least partly controlled by local reproduction (Schultz and Cowen 1994, Green et al. 2015). Because scientists have not yet observed stockrecruitment functions for coral reef fishes, constant recruitment remains the most appropriate approach for modeling reproduction. In this model, a fixed number of $1-\mathrm{cm}$ juveniles ( $\mathrm{n}$ $=6$ ) enter the population at every time step.

\section{(ii) Somatic growth}

Individual growth is a function of age that follows the von Bertalanffy growth equation:

$$
L(t)=L_{\mathrm{inf}}(1-\exp (-K / 52)) \times\left(\text { age }-t_{0}\right)
$$

where $L_{\text {inf }}$ is the maximum size, $K$ is the growth coefficient, and $t_{0}$ is the theoretical age at which fish length is zero, although length never truly equals zero. Growth rate is divided by 52 to convert to weekly increments.

We used the following length-weight relationship to convert fish length, i.e., fork length in centimeters, to fish weight, i.e., total live weight in kilograms (Froese and Paulv 2017):

$$
\text { weight }=0.0257 \times L^{\wedge} 2.93
$$

\section{(iii) Maturation and sex change}

Fish enter the model as juveniles and then transition to the initial phase and, finally, to the terminal phase. Maturation into the initial phase occurs automatically when fish become larger than $15 \mathrm{~cm}$ (van Rooij et al. 1996b).

The mechanism that cues initial-phase fish to transition to the terminal life phase is unknown for stoplight parrotfish. However, Caribbean parrotfish have been shown to transition at smaller sizes when population size and structure are altered by fishing (Choat et al. 2003, Hawkins and Roberts 2004). Therefore, we assume that the probability of an individual transitioning from initial to terminal phase is a function of size, and the probability of transitioning at any given size can vary if the size structure of the population changes. We previously explored outcomes associated with one fixed and three flexible rules that might govern sex change in stoplight parrotfish (Pavlowich et al. 2018). We did not find large differences between the different flexible rules, so we used only one of them. Initial-phase fish have a probability of transitioning to terminal phase based on the proportion of adult fish in the population that are smaller than they themselves are. The probability of sex change at a given length is calculated according to the equation proposed by Alonzo and Mangel $(2004 b)$ as a possible sex change rule:

$$
p_{\mathrm{C}}(L)=\frac{1}{1+\exp (-q(\text { prop. smaller }- \text { prop. smaller } \mathrm{C}))}
$$

where the length of an individual $(L)$ determines a fish's relative size in the population (prop.smaller), and there is some proportion at which fish have a $50 \%$ chance of transitioning (prop.smaller ${ }_{C}$ ). Therefore, the probability of transitioning at a given length changes as the number of fish larger and smaller than that length changes. We define $q$ as the rate at which sizes gain probability of transition. When a fish is selected to transition to the terminal phase, it becomes "transitional" phase for 4 weeks and then becomes terminal phase.

\section{(iv) Natural mortality}

Fish in the model experience mortality from natural causes and from fishing. Natural mortality has two components, predation while the fish are small and senescence when the fish become old (O'Farrell et al. 2015). Bozec et al. (2016) described the probability of dying because of natural causes with two logistic equations that we adopted for our model: 


$$
p_{\text {M.pred }}=\text { a.pred } \times \exp \left(\text { b. pred } \times L / L_{\text {inf }}\right)
$$

$$
p_{\text {M.sen }}=\text { a.sen } \times \exp (\text { b.sen } \times L)
$$

where a.pred scales predation mortality and b.pred determines how quickly it decreases with size. For simplicity, we modeled the probability of dying because of senescence as a function of length, assuming that age and length are strongly correlated. The parameters a.sen and b.sen control how much and how quickly mortality because of senescence is imposed on fish.

\section{(v) Fishing mortality}

The model uses instantaneous fishing mortality, $F$, to calculate the probability each fish has of dying because of fishing. This variable encapsulates various aspects of fishing pressure such as the number of fishers, how much time each fisher commits to fishing, gear efficacy, and the proportion of fish encountered that are pursued (Salas and Gaertner 2004). We do not attempt to dissect these aspects of fishing but acknowledge their contribution in real life. In the model, annual instantaneous fishing mortality is divided by 52 to convert it to weekly time steps. Size and life-phase selectivity modify fishing pressure to determine the probability that an individual has of dying.

Size selectivity ranges from zero to one, with one being fully susceptible to fishing and the probability of dying equal to the given level of fishing pressure. The equation is the logistic function:

$$
s(L)=1 /\left(1+\exp \left(-r\left(L-L_{\mathrm{f}}\right)\right)\right.
$$

where $L_{\mathrm{f}}$ is the size at which fish have a $50 \%$ chance of being selected, and $r$ is a rate parameter that controls the steepness of the curve.

Life-phase selection can take three values: any life phase available (except juveniles), terminal only, or initial only. If a fish's life phase can be taken by the fishery, its probability of dying is the following:

$$
p_{\text {M.fishing }}(L)=\exp \left(-\frac{F}{52} \times s(L)\right)
$$

If a fish's life phase or size is prohibited from harvest, its probability of dying because of fishing is zero. Note that in the results, we plot model outcomes versus fishing mortality given as the probability of a fully selected fish dying annually. Doing so keeps the internal model equations in a familiar format for fishery models and presents the results in a more generic, easily understood format. Instantaneous fishing mortality is converted to annual fishing mortality according to the following equation (Haddon 2011):

$$
\text { proportional. annual. mortality }=1-\exp (-F)
$$

The model randomly selects the order for the mortality functions to be applied for every fish at every time step, i.e. fishing mortality, then natural mortality, or vice versa. This avoids problems associated with assuming that one always precedes the other.
We assumed that fishers did not compensate for reduced availability of certain sizes and life phases by altering selectivity or increasing fishing effort. The assumption of constant selectivity works reasonably well for nonselective fishing gear, such as gill nets or fish traps. However, this assumption may be violated, to a greater or lesser degree, for selective gear types, namely spearfishing, in a multispecies fishery that gives fishers the ability to target individual fish. Also, the ability to target individual fish or return unwanted fish to the water alive is, in fact, a necessary element for the minimum-size and terminalphase-fish-only regulations to be effective. Regarding compensation via effort adjustment, we had no information to evaluate whether fishers would alter their fishing effort in response to a change in parrotfish regulations. Though fishers may direct proportionally more effort to other, unregulated species, doing so would not change our outcomes of interest: stoplight parrotfish biomass and the value of their harvest. Therefore, we did not include any mechanism for increasing fishing mortality onto available segments of the population when others became prohibited.

\section{Parameter estimation}

We estimated parameter values that reproduced the size structure and fish density of stoplight parrotfish in Buen Hombre to represent a highly fished reef and plot the trajectory of recovery from a realistic starting point. The first step in parameterizing the model was to identify the most important characteristics of the size distribution. These included the following defining attributes of the Buen Hombre population: (1) most fish were between 10 and $15 \mathrm{~cm}$ long, (2) the distribution had an increasing number of individuals in the size classes between 0 and $15 \mathrm{~cm}$, and (3) there were relatively few fish in the $25-$ to $30-\mathrm{cm}$ class and few to no fish larger than $30 \mathrm{~cm}$.

We manually searched the parameter space of the model to find parameter combinations that produced populations with the previously described characteristics of the Buen Hombre population because these three characteristics cannot be reduced into a single metric of goodness of fit (Grimm et al. 2005). This involved adjusting four model parameters to improve the fit to the Buen Hombre fishery: the number of recruits entering the population at each time step (n.recruits), two parameters that define the magnitude and slope of the predation mortality curve (a.pred and b.pred), and the amount of fishing pressure placed on the population. The first three parameters determine the shape of the size distribution of small fish, and fishing pressure determines the distribution of large individuals. We have no data to evaluate whether mortality because of senescence or the sex change rule would change in a heavily fished population, and thus we left these variables unchanged from our previous parameterization (Pavlowich et al. 2018).

We fit a curve to the 2014 catch data to describe the size selectivity of the fishery. To do so, we used nonlinear least squares to fit a logistic curve to the catch data following Alonzo and Mangel (2004a). Fishers most frequently caught fish that were 20 -cm fork length (Fig. 2). Twenty-centimeter fish accounted for $15.6 \%$ of the catch, and we considered anything this size or larger fully selected (i.e., selection $=1.0$ ). This assumes that fishers encountered additional smaller fish in the fishing area but did not catch these smaller fish because they prioritized targeting larger 
Table 2. Parameter definitions and values from our model when fitted to an unfished fishery (Bonaire; Pavlowich et al. 2018) and a heavily fished fishery (Buen Hombre). "NA" stands for "not applicable," which applies to model parameters for fishing mortality that were not present in the model of the unfished Bonaire population.

\begin{tabular}{|c|c|c|c|c|}
\hline Parameter & Definition & $\begin{array}{l}\text { Value Fitted to } \\
\text { Bonaire }\end{array}$ & $\begin{array}{l}\text { Value Fitted to Buen } \\
\text { Hombre }\end{array}$ & Source \\
\hline \multicolumn{5}{|l|}{ Reproduction } \\
\hline \multirow[t]{2}{*}{$\mathrm{n}$} & Number of recruits entering the population & 46 & 6 & Bozec et al. (2016) \\
\hline & Size at recruitment & $1 \mathrm{~cm}$ & $1 \mathrm{~cm}$ & Choat et al. (2003) \\
\hline \multicolumn{5}{|l|}{ Growth } \\
\hline$L_{\text {inf }}$ & Maximum length & $39 \mathrm{~cm}$ & $39 \mathrm{~cm}$ & Bozec et al. (2016) \\
\hline$K$ & Growth rate & Function of $L_{\text {inf }}$ & Function of $L_{\text {inf }}$ & O'Farrell et al. (2015) \\
\hline \multicolumn{4}{|l|}{ Maturation } & van Rooij et al. $(1996 b)$ \\
\hline \multicolumn{5}{|l|}{ Sex change } \\
\hline freq.smaller ${ }_{c}$ & $\begin{array}{l}\text { Size quantile at which fish have a } 50 \% \\
\text { chance of changing sex }\end{array}$ & 1.0 & 1.0 & Calibration \\
\hline$q$ & Transition rate & 11 & 11 & Calibration \\
\hline \multicolumn{5}{|l|}{ Natural mortality } \\
\hline a.pred & Predation scalar & 2.4 & 0.5 & Calibration \\
\hline b.pred & Predation rate & -1.26 & -2 & Calibration \\
\hline a.sen & Senescence scalar & 0.00011 & 0.00011 & Calibration \\
\hline b.sen & Senescence rate & 5.2 & 5.2 & Calibration \\
\hline \multicolumn{5}{|l|}{ Fishing mortality } \\
\hline$L_{\mathrm{F} 50}$ & Length at $50 \%$ chance of selection & NA & 16.8 & Buen Hombre data \\
\hline$r_{\text {selectivity }}$ & Slope of selectivity curve & NA & 1.02 & Buen Hombre data \\
\hline$F$ & Fishing pressure & 0 & 2.5 & Calibration \\
\hline
\end{tabular}

fish. We further assumed that no size above $20 \mathrm{~cm}$ was as numerous in the catch because they were less abundant, not because fishers did not target these sizes. We then fit the selectivity function to the histogram data in Figure 2. The best-fit parameter values were $r=1.02$ and length at $50 \%$ selection $=16.8 \mathrm{~cm}$.

Fig. 2. Size distribution of free divers' catch in 2014 (gray histogram) and the size selection (black curve) fitted to those data. Selection $=1 /(6.41 \times(1+\exp (-1.02($ length -16.8$))))$.

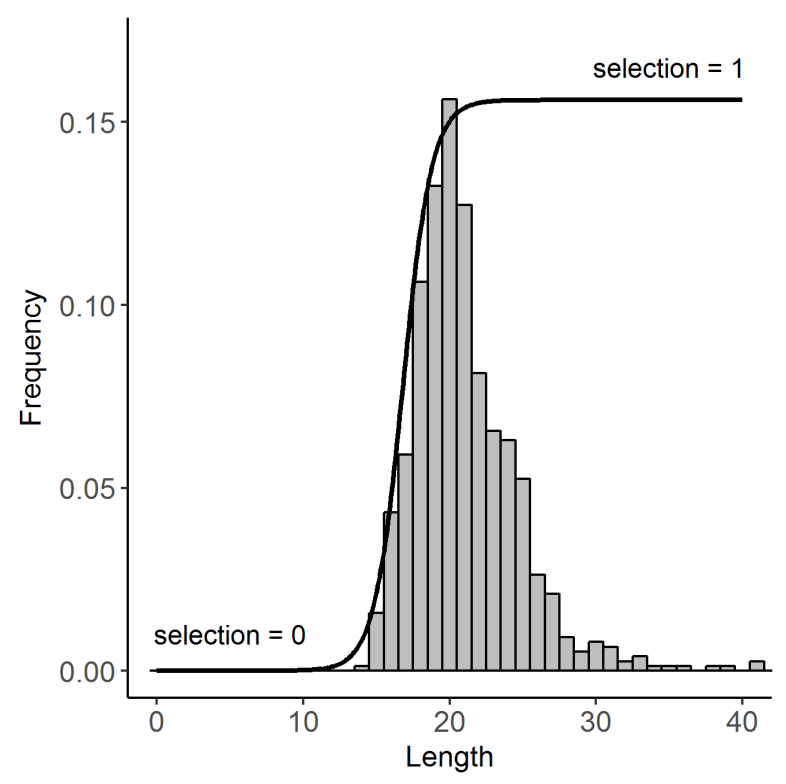

Calibrating recruitment, juvenile mortality, and fishing mortality We systematically tested and found parameter combinations that produce reasonably good fits to our observed population, based on the main characteristics described previously. Recruitment and the two parameters that control juvenile mortality, a.pred and $b$. pred, all combine to control the number of fish between 0 and 15 $\mathrm{cm}$. Depending on the values of the mortality parameters (a.pred and b.pred), recruitment could be between 4 and 6 individuals per week and generate reasonable frequencies for the 0 - to $5-\mathrm{cm}$ size class. The mortality parameters partially controlled the number of fish in this first size class, as well as frequencies between 5 and $15 \mathrm{~cm}$. We found that the y intercept, a.pred, did best around 0.5 or below. The fit was, of course, dependent on the value of b.pred, which, when paired with a.pred $=0.5$ and 6 weekly recruits, performed well when set to -1.75 . These were our final parameter values used in the model. With the first part of the size distribution reasonably well fit, we sought to find the level of fishing pressure that would recreate the right-hand side most accurately when paired with the empirically derived size-selectivity parameters and the previously fixed senescence parameters (a.sen and b.sen). Instantaneous annual fishing mortality had to be set to 2.5 to truncate the distribution around $30 \mathrm{~cm}$ and have approximately 17 fish in the $25-$ to $30-\mathrm{cm}$ size class, 2 of our criteria for fitting to the observed size distribution. Together, these parameter values (Table 2, "calibration") produce a size structure with similar characteristics to those we observed in Buen Hombre. We present a sensitivity analysis on these parameters in the Results.

\section{Fishing experiments}

We identified management options through formal and informal interviews and conversations with fishers, managers, and a local nongovernmental organization (NGO), AgroFrontera, between 2012 and 2016 (Wilson et al. 2016), as well as drawing on ideas 
Table 3. Management options identified and tested.

\begin{tabular}{|c|c|c|}
\hline Intervention & Levels/Details & Rationale \\
\hline Life phase restriction & Only harvest terminal-phase fish & $\begin{array}{l}\text { Pavlowich et al. (2018) identified the protection of initial-phase fish } \\
\text { as being most valuable for maintaining abundant stoplight } \\
\text { parrotfish (Sparisoma viride) populations. }\end{array}$ \\
\hline \multirow[t]{3}{*}{ Size restriction } & $>20 \mathrm{~cm}$ & $\begin{array}{l}\text { Fishers have recommended banning third-class fish, which are } \\
\text { almost all less than } 20 \mathrm{~cm} \text { long. }\end{array}$ \\
\hline & & Size restriction recommended by Bozec et al. (2016) \\
\hline & $>30 \mathrm{~cm}$ & \\
\hline \multirow[t]{2}{*}{ Closed season } & 3 months & $\begin{array}{l}\text { Corresponds to the length of closed seasons for lobster (Panulirus } \\
\text { argus) and conch (Strombus gigas) in the Dominican Republic }\end{array}$ \\
\hline & 6 months & $\begin{array}{l}\text { Worthwhile to investigate this higher level of protection given } \\
\text { parrotfish's importance for reef health }\end{array}$ \\
\hline $\begin{array}{l}\text { Reduce fishing pressure } \\
\text { (could be achieved via input controls, } \\
\text { such as lowering the number of fishers or }\end{array}$ & $-10 \%$ & $\begin{array}{l}\text { This minor adjustment to fishing may be more politically feasible } \\
\text { but less likely to rebuild the population. }\end{array}$ \\
\hline $\begin{array}{l}\text { boats, or output controls, such as catch } \\
\text { limits, that effectively reduce fishes' } \\
\text { probability of dying because of fishing) }\end{array}$ & $-50 \%$ & $\begin{array}{l}\text { This major adjustment to fishing is more politically difficult to } \\
\text { implement but is more likely to rebuild populations. }\end{array}$ \\
\hline
\end{tabular}

from the coral reef management literature (Heppell et al. 2006, Bozec et al. 2016) and our previous work (Pavlowich and Kapuscinski 2017, Pavlowich et al. 2018). We identified four types of management, for three of which we specified two levels of intensity, resulting in seven potential management options. Table 3 presents the interventions and their details.

We tested each intervention by running simulations for 5 years with the estimated fishing parameters for Buen Hombre; 5 years was enough time for the population size and structure to stabilize. We then applied the intervention for another 5 years of simulation. The model stabilized to the estimated fishing conditions in Buen Hombre after the first 3 years, after which we calculated the mean and standard deviation from the next 2 years to represent preintervention values of population biomass. After we began to apply the management intervention, we allowed the model 3 years to adjust to the new fishing regime and calculated the mean for the 2 final years of simulation. We repeated each simulation just 3 times because variability between runs was low (see variability in model runs in Fig. 3). From these simulations, we tracked population biomass and the value of fishers' catch for the entirety of each simulation. This allowed us to examine the effects of management options through time. We also calculated the final values of several other outcome metrics that help clarify effects on population and catch: average length of adult fish; the ratio of female biomass when fished to female biomass when unfished, i.e., spawning potential ratio (SPR; Nadon et al. 2015); number of fish caught; and weight of fish caught. The value of the catch was highly variable each week, so we used the 6-month moving average of each run to describe its trajectory. We calculated the mean catch value before and after the management intervention the same way as we did for biomass. Additionally, we calculated the time it took for the moving average to return to prior levels after implementing the intervention. We did this because the longer catch value is depressed, the harder it will be on fishers and the less likely fishers will be to comply with a regulation.

\section{Sensitivity analysis}

We tested the model's sensitivity to key variables by altering parameter values from their base value and then assessing the relationship to population and harvest outcomes (Bozec et al. 2016). We randomly chose parameter values between $\pm 25 \%$ of the base value and plotted them against population size (Fig. 4, top panel) and value of the catch (bottom panel). We included the price variables because they change regularly, and some stakeholders consider them to be a point of leverage for changing fishers' behavior (F. V. Payton, executive director of AgroFrontera, personal communication).

\section{RESULTS}

\section{Current fishery conditions in Buen Hombre}

We observed 206 stoplight parrotfish in 2013 and 146 in 2013. The size structure of the stoplight parrotfish population in Buen Hombre was qualitatively very different than that observed in unfished Bonaire (Fig. 1) as expected for a heavily fished fishery. The population in Buen Hombre had fewer large fish, and the frequency of fish in the smallest size classes tended to increase after recruitment, rather than decrease for the first $15-20 \mathrm{~cm}$. We acknowledge that population size and structure measured in Buen Hombre at the time of sampling may have been transitory, i.e., they are unlikely to represent a constant, stable state. Our observations came from 2 sampling seasons over 2 consecutive years, whereas the data from Bonaire (van Rooij et al. 1996a) were made over the course of 4 years, during which the population was quite stable. Other published size distributions of stoplight parrotfish share characteristics of either our data or the data from Bonaire. Koltes (1993) described a population in Turks and Caicos similar in structure to that in Buen Hombre: relatively few small fish, followed by maximum frequency at the middle sizes and diminishing frequencies through the largest sizes. Paddack et al. (2009) reported a size distribution in the Florida Keys more similar to that of Bonaire, with many new recruits, declining frequencies through the middle sizes, and another peak in the upper size classes. We observed a sex ratio of 2.42 (ratio of initial phase to terminal phase [IP:TP]) in 2014. 
Fig. 3. The responses of population biomass (top panel) and catch value (bottom panel) to fishery management interventions (yaxes of panels) through time. Each blue path depicts a model run. In the bottom panel, faint lines show weekly catch values, and heavy blue lines show the 6-month moving average of catch value. Populations in all runs started with 30 individuals; red arrows indicate when rules were first applied. Minimum sizes are in centimeters, and closed seasons are in months.
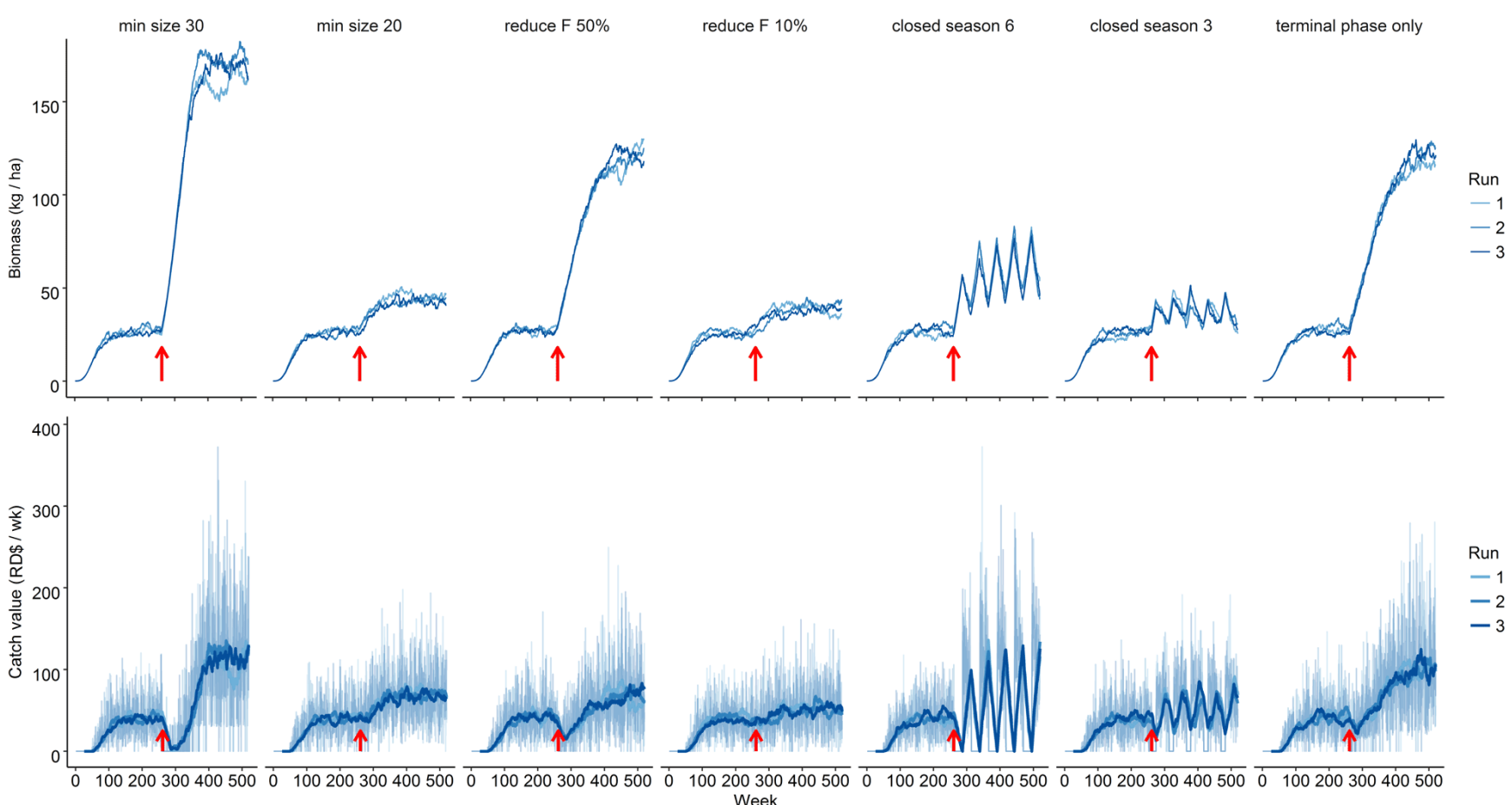

Fig. 4. Sensitivity of population size (top panel) and catch value (bottom panel) to perturbations in fitted model parameters (y-axes of panels). a.pred and b.pred are unitless, n.recruits is the number of individuals entering the population per weekly time step, fishing mortality is expressed as an instantaneous value, fork length at $50 \%$ fishery selectivity is in centimeters, and the price variables are expressed in Dominican pesos (RD\$).
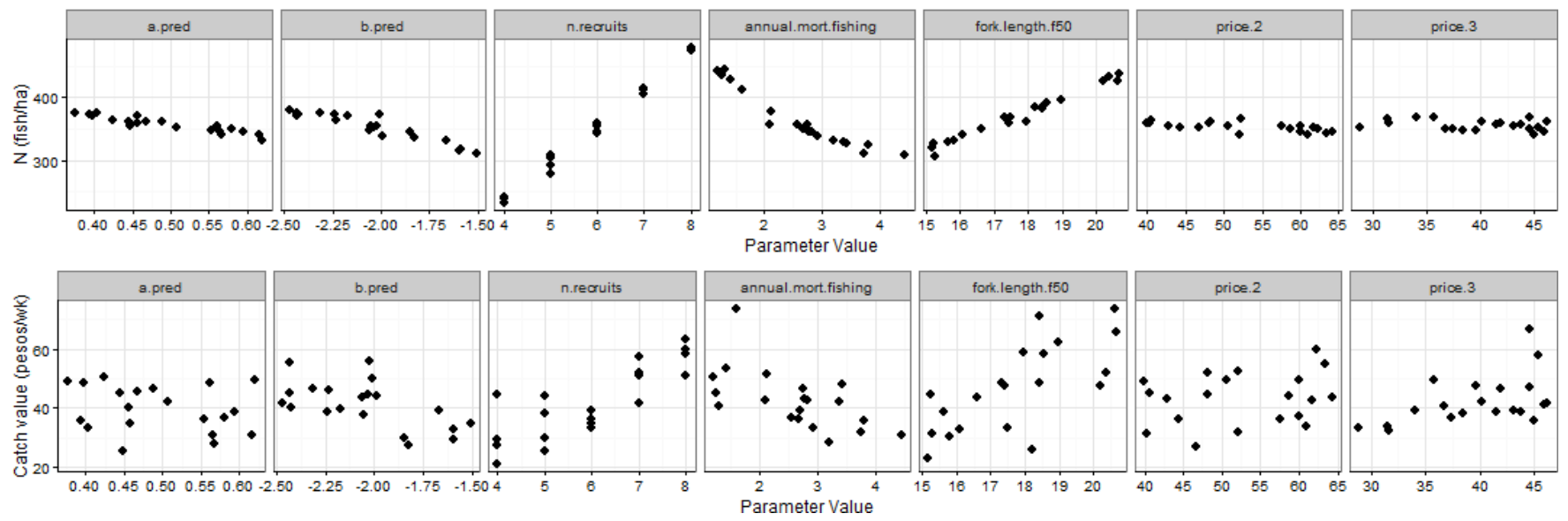

\section{Fishery intervention experiments}

Total population biomass, population size, and mean length ultimately increased after 3 simulated years with the implementation of almost every intervention (Fig. 3, Table 4). The only exception was that mean length decreased slightly under an annual 3-month closed season. All interventions, except for the closed seasons, showed biomass increases immediately after their implementation. Biomass increased for a period of 1 to 2 years and then came to a steady state, with some variation around it, under each new fishery regulation. When closed seasons were 
Table 4. Mean population and catch characteristics of 3 runs after 5 years under the different harvest control rules. IP:TP, ratio of initial phase to terminal phase; SPR, spawning potential ratio.

\begin{tabular}{|c|c|c|c|c|c|c|c|c|}
\hline & No Regulation & $\begin{array}{l}\text { Minimum Size } \\
30 \mathrm{~cm}\end{array}$ & $\begin{array}{l}\text { Minimum Size } \\
20 \mathrm{~cm}\end{array}$ & $\begin{array}{c}\text { Reduce } F \\
50 \%\end{array}$ & Reduce $F 10 \%$ & Closed 6 mo & Closed $3 \mathrm{mo}$ & Terminal Only \\
\hline \multicolumn{9}{|l|}{ Population } \\
\hline $\mathrm{N}$ & 356 & 703 & 419 & 570 & 386 & 439 & 388 & 523 \\
\hline (cm) & 19.8 & 24.5 & 20.3 & 24.4 & 20.7 & 21.7 & 19.7 & 23.5 \\
\hline SPR & 0.16 & 0.86 & 0.27 & 0.53 & 0.20 & 0.28 & 0.20 & 0.48 \\
\hline $\begin{array}{l}\text { Sex ratio (IP: } \\
\text { TP) }\end{array}$ & 2.50 & 1.33 & 2.46 & 1.30 & 1.94 & 1.65 & 2.08 & 2.20 \\
\hline \multicolumn{9}{|l|}{ Catch } \\
\hline $\begin{array}{l}\text { Number (\#/ } \\
\text { wk) }\end{array}$ & 4.63 & 3.29 & 4.50 & 3.46 & 4.45 & 4.25 & 4.57 & 4.30 \\
\hline $\begin{array}{l}\text { Weight (kg/ } \\
\text { wk) }\end{array}$ & 0.76 & 2.06 & 1.22 & 1.28 & 1.03 & 1.18 & 1.04 & 1.64 \\
\hline
\end{tabular}

in place, biomass increased quickly and then decreased sharply when the fishery opened up again. This pattern continued as the fishery cycled between open and closed seasons. The magnitude of the increase in biomass varied substantially between interventions, from more than a $500 \%$ increase to only a $38 \%$ increase. Enacting a minimum size limit of $30 \mathrm{~cm}$ produced the greatest increase in fish biomass at 518\% above the preintervention level. Reducing fishing mortality by half and only harvesting terminal-phase individuals also generated substantial increases in biomass above current levels, $341 \%$ and $174 \%$, respectively. Creating 3- or 6-month closed seasons, setting a minimum size of $20 \mathrm{~cm}$, or reducing fishing by only $10 \%$ led to only modest increases in biomass. The long-term responses of other population metrics, population size and mean length, showed a similar pattern as biomass.

The final mean value of the catch also increased with each management option (Fig. 3), because the rebuilt populations ultimately provided larger fish that were worth more money (Table 4). There was much more variability around catch value than total biomass, which led us to use the 6-month moving average to represent the trend through time. The biggest economic gains came from the interventions that also led to the biggest increases in fish biomass. A minimum size of $30 \mathrm{~cm}$ increased catch value by $177 \%$, and catching only terminal-phase fish doubled the value of the catch. The next biggest increase in catch value, reducing fishing mortality by $50 \%$, was only half as much as the increased value from catching only terminal-phase fish, and the other interventions resulted in even smaller increases in value. Closed seasons generated oscillating catch values, as they did for biomass, and led to an overall increase in value when averaged over an entire year. Under the scenarios of a $30-\mathrm{cm}$ minimum size and reducing fishing by $50 \%$, the number of fish caught decreased, but the increase in size and value more than compensated for the slightly fewer captures. In contrast to total biomass, the economic gains were not immediately realized for any regulation. Catch value initially dropped when interventions were first enacted. In all cases, catch value eventually recovered and surpassed preintervention levels.

Perhaps the biggest challenge for stakeholders hoping to implement any of these regulations can be seen in the initial decline in catch value. The time it took catch value to recover to preintervention levels varied depending on the severity of the fishery restriction. The intervention that led to the biggest gains in biomass and catch value, setting a minimum size of $30 \mathrm{~cm}$, also took the longest for catch levels to recover. Catch value was lower than it initially was for more than 20 months, and that included many weeks in which there was no catch at all. Catching only terminal-phase fish, another well-performing regulation, suppressed catch value for 1 year. Reducing fishing pressure by $50 \%$ kept catch value down for 1 year and 4 months. Setting a minimum size of $20 \mathrm{~cm}$ led to virtually no initial decline in catch value and accordingly small increases in biomass.

SPR increased under each regulation as well (Table 4). Fisheries scientists often consider SPRs between 0.2 and 0.3 a threshold for overfishing (Restrepo et al. 1998). In our simulations, implementing no regulation, a minimum size of $20 \mathrm{~cm}$, fishing mortality reduction of $10 \%$, or closed seasons 3 or 6 months long all resulted in SPRs lower than 0.3. A minimum size of $30 \mathrm{~cm}$ produced the best SPR results, with nearly as much female biomass as a completely unfished population.

\section{Sensitivity analysis}

The model was more sensitive to recruitment and fishing mortality than to other life history parameters (Fig. 4). The number of recruits and the size at selection (fork.length.f50) had strong positive relationships with population size, and annual fishing mortality had a strong inverse relationship. Early life mortality parameters, a.pred and b.pred, also showed clear relationships, but their effect on population size was small. Price had no effect on population size because the model had a simplifying assumption of no feedback to fishing pressure or fisher behavior. This assumption may hold for situations where fishers have few livelihood options and few options for which fish to harvest, as is the case in Buen Hombre. With such constraints, fisher response to changes in price will be limited. Catch value responded to each variable in the same direction as population size, only the effect contained much more variation, as it did in our management simulation results. Somewhat surprisingly, the price variables still did not exert much effect on catch value. This demonstrates how the availability and size of fish influences fishery revenue much more than the price paid per pound. 


\section{DISCUSSION}

We sought to identify management options that maximize recovery of stoplight parrotfish biomass while minimizing negative impact on fishers' livelihoods. All the options showed trade-offs between these ecological and social objectives. The choice of a particular type of intervention rests on stakeholders and a careful examination of priority goals and acceptable levels of specific outcomes over time. This reinforces the importance of collaboration between scientists and decision makers throughout the process of developing a management plan.

\section{Predicted management outcomes}

The management options we tested present fishers and managers with both win-wins and trade-offs depending on the time frame considered. We found that every restriction we tested led to improvements in both stock status and fishery revenue in the long run. However, we also found temporal trade-offs in that the interventions that produced the best outcomes in the long term took the hardest financial toll on fishers in the short term. Those interventions produced the greatest initial dips in catch value and took the longest for catch value to recover to preintervention levels. Indeed, the conflict between long-term well-being and short-term sacrifice commonly appears in natural resource management (Mardle and Pascoe 2002, Chapin et al. 2009).

The analyses of various management options can help stakeholders to identify and compare specific trade-offs among options, identify ways to mitigate the negative consequences of unavoidable trade-offs, and thus make better informed decisions about pursuing a given option, mixture of options, or modifications of these options. Overall, the model predicted that regulations that restricted certain types of fish, i.e., size restrictions and the terminal-only restriction, produced better economic results for similar levels of population biomass gain than did restrictions on effort. Of particular interest, the terminalonly restriction yielded lower biomass gains than reducing fishing by $50 \%$, but fishing only the terminal phase led to substantially higher catch value. When fishing pressure was reduced by $50 \%$, biomass in all sizes increased to some extent, but this option does not address the current practice of catching small fish that are still undergoing fast growth. Furthermore, reducing fishing pressure by $50 \%$ would likely deeply disrupt many fishers' livelihoods, whether half of fishers were excluded, all fishers were allowed to fish half as much, or half of the fishing area was converted to a no-take zone. In practice, these 3 ways of reducing fishing mortality by $50 \%$ would have substantially different outcomes. They would also require tremendous effort to reduce fishing by participation, time, or space. Had we tested other levels of reductions in fishing mortality, we may have found a level that could lead to good population rebuilding with less disruption to income. Our goal, however, was to explore a broad range of regulation types, not to find the optimal level of any one intervention. Doing so better matches the scope and level of detail needed in heavily fished Caribbean reefs where management is currently weak or just beginning.

The terminal-phase-only regulation also performed economically better than other possible interventions in important ways. Compared to the $30-\mathrm{cm}$ size restriction, it allowed fishers to continue catching some fish, albeit fewer fish overall, while the population was rebuilding. Furthermore, the average catch value returned to preintervention levels 8 months earlier than the 30 $\mathrm{cm}$ restriction. When catching only terminal-phase fish, the release from fishing mortality allowed the initial-phase component of the population to increase maximally because there were no losses to fishing. This in turn provided a larger pool of fish available to transition to the terminal phase and increased the frequency of fish in the upper-middle size classes (i.e., 20- to $25-\mathrm{cm}$ and $25-$ to $30-\mathrm{cm}$ classes). Therefore, the rate of replenishment of terminal-phase fish increased, and terminalphase fish were larger and more valuable.

Closed seasons of 3 and 6 months performed less well than the terminal-phase-only restriction and compared with the other management options. Because fishing mortality remained high during the months when fishing was allowed, the population and income fluctuated strongly. A 6-month closed season did substantially increase the average population size, but a 3-month closure hardly increased population size. The lack of positive outcomes from the closed seasons comes from the assumption, based on empirical observations, that this species spawns during all or most of the year and does not have annual migrations or aggregations (Robertson and Warner 1978, Koltes 1993, van Rooij et al. 1996b). Because of this, population size quickly declined, in the direction of equilibrium population size under status quo fishing mortality, whenever fishing was allowed, i.e., for 6 or 9 months of the year. With respect to livelihoods, fishers may be able to adapt to times when this species would not be available, especially if strategically implemented to not overlap with other established closed seasons for lobster (Panulirus argus) and conch (Strombus gigas). However, it would also present another challenge for fishing communities with few livelihood options. Determining communities' preferences would require further consultation.

Implementing regulations in an incremental manner might create a smoother transition for fishers forced to deal with temporarily reduced catch. Revenue from fishing would not decline as steeply in the short term if managers first implemented a terminal-only rule and then a 30-cm lower size limit some time later (e.g., 2 years later). Allowing terminal-phase fish to be caught would immediately reduce fishing mortality but still permit some harvest, whereas a $30-\mathrm{cm}$ minimum size would initially leave fishers without any legal-sized fish to catch. It would also allow the population to recover substantially under the terminal-phaseonly rule, which would then make a $30-\mathrm{cm}$ size limit less disruptive to fishers' livelihoods. Furthermore, the difference between initialand terminal-phase individuals is easier for fishers to distinguish visually (Pavlowich et al. 2018) than whether a fish is larger or smaller than a specific size. This advantage of the terminal-only regulation would be easier to follow by spearfishers making selection decisions underwater and by anyone monitoring catch, such as government officials or other fishers, at the landing point. It would not, however, reduce fishers' financial dependence on stoplight parrotfish. Instead, it could create stronger dependence, making it even more difficult to eventually implement a full prohibition on this species. Any newly imposed fishing restrictions will likely disrupt some people's ability to support themselves from fishing alone (Cinner 2014). Governments and involved NGOs should accompany heightened regulation with support for alternative livelihoods and, potentially, short-term financial safety net programs. For example, temporary subsidies could help 
fishers during the model's predicted 1-year time period, after which population recovery is predicted to restore catch value. Additionally, the multispecies nature of coral reef fisheries provides fishers with opportunities to catch species other than parrotfish to compensate for the decrease in fish availability. However, this would raise concerns about the impacts on other species whose ecological roles might be important for system functioning.

The model estimated sex ratios around 2.5 (IP:TP) at the levels of fishing pressure and size selection estimated for Buen Hombre. This result closely matches the sex ratio of 2.42 that we observed in Buen Hombre. However, other stoplight parrotfish populations that are fished have had higher sex ratios compared with unfished populations (van Rooij et al. 1996b, Hawkins and Roberts 2004, O'Farrell et al. 2016). Although previous studies showed skewed sex ratios in highly fished reefs, the relatively normal sex ratio in Buen Hombre calls into question how ubiquitous that phenomenon is and the extent to which parrotfish can maintain a typical sex ratio while undergoing fishery exploitation. Clearly, our limited understanding of the mechanisms driving sex change in parrotfish requires more research before we can accurately predict the impacts of fishing on the reproductive behavioral ecology of these species.

\section{Multispecies context}

We investigated a single species, but the dynamics we uncovered should generally apply to most parrotfish species. We would expect populations of most species to react qualitatively similarly to the types of regulations we tested, although the magnitude of the effects is likely to be different. For example, the redband parrotfish (Sparisoma aurofrenatum) would probably react less to size restrictions because its maximum size is only slightly larger than the size at which fish are harvested in Buen Hombre (Froese and Pauly 2017). Therefore, most redband parrotfish are already able to live to maturity, and a small proportion of the population is affected by fishing mortality. Another consideration is that species with slower growth rates would be expected to recover from initially lost catch value more slowly, because it will take longer for the larger fish to develop. Additionally, each parrotfish species might have different sex change rules, which could produce different responses, especially in the sex ratio. Caribbean parrotfish species change sex at different sizes depending on the structure of the population, and thus, all species ought to be able to compensate to some extent for increased fishing mortality on terminal-phase fish (Choat et al. 2003, Hawkins and Roberts 2004). However, studies of parrotfish and other protogynous hermaphrodites have shown worrisome sex-ratio skew in fished populations (Alonzo and Mangel 2004b, Heppell et al. 2006, O'Farrell et al. 2016). Our simulations suggest that this may be because of high fishing mortality on initial-phase fish in addition to the impacts of intense fishing on the terminal phase. Close monitoring should accompany any implementations of a lifephase-based regulation for fishing to avoid reproductive failure if sex change in these species cannot keep up with the rate of extraction (Heppell et al. 2006, Alonzo et al. 2008).

Another management consideration is the effect of applying the simple regulations we considered to all species in a multispecies reef fishery. Each of the regulations we modeled should reduce fishing mortality on the species to which they are applied and thus help rebuild biomass in exploited populations. However, the concomitant decrease in catch value immediately after the application of each regulation (see Fig. 3) would have an even greater negative financial impact on fishers if it included lost revenue from multiple species. Some regulations, such as applying a 30-cm size limit to all species, would all but shut down the entire fishery in Buen Hombre for a period of time, making this strategy socially nonviable. However, placing restrictions on parrotfish alone could lead fishers to switch their target species and, hence, pursue other fish with greater intensity (Cinner 2011). Although much attention has been recently given to the necessity of herbivory for coral reef health (Bellwood et al. 2004, Hughes et al. 2010), other functional groups undoubtedly play important roles in maintaining ecosystem structure and resilience. Therefore, it will be important to monitor fishery and fish community responses to avoid unintended consequences. Beyond the impacts of new regulations on fishers' livelihoods per se, the extent to which fishers might shift fishing pressure to alternative, nonherbivorous species provides an important reason to explore financial bridging strategies that might limit fishers' temporary declines in catch revenue.

\section{Future work}

Several areas of research could expand the scope of our study and improve the accuracy and precision of its predictions. Incorporation of other parrotfish species, and then nonparrotfish species, into the same modeling framework would shed light on community rather than population impacts of the proposed management interventions. With this expansion would come a need for more complex submodels of species interactions, community dynamics, and fishers' fishing behavior, particularly regarding selection decisions and their ability to shift their efforts when certain types of fish are prohibited. The complexity of these new submodels would also require empirical observations, such as our previous work on spearfishers' foraging behavior (Pavlowich and Kapuscinski 2017), to make them believable. Similarly, an improved understanding of the cues and mechanisms of sex change in parrotfish could either validate the current model or suggest improvements. Also, longer term observations of parrotfish populations in Buen Hombre would lend further support or offer a chance for refinement of model parameters and improve the accuracy of model predictions. Perhaps most importantly, implementing any of the tested regulations and monitoring ecological, economic, and behavioral responses in the system would provide crucial data for model verification and improvement.

\section{CONCLUSIONS}

We used an agent-based modeling platform to bring together the best available information on ecologically and economically important stoplight parrotfish and predicted the positive and negative outcomes of potential management interventions. We tailored the model and questions to the social-ecological context where management is most needed: small-scale reef fisheries in developing countries. We found that restricting catch to only terminal-phase fish could provide a bridging strategy from a complete lack of regulation on this species to more stringent and ecologically restorative restrictions. In situations of high resource dependence, degraded ecosystems, and low levels of governance, stakeholders and scientists should first seek strategies for making 
the ecological and social situation better, not necessarily optimal, as a step along the complicated path toward sustainably managed fisheries.

Responses to this article can be read online at: http://www.ecologyandsociety.org/issues/responses. $\mathrm{php} / 10799$

\begin{abstract}
Acknowledgments:
We would like to thank the community of Buen Hombre and Dr. Freddie Payton of the NGO AgroFrontera for their support and friendship while conducting this research. We thank the Ministry of the Environment and Natural Resources, "Medio Ambiente," for allowing us to work in the area and for being open to discussions regarding local fisheries management. We thank Molly Wilson, Jill Britton, and Sarah Caughey for their assistance in the field. We owe thanks to Shay O'Farrell and Jules van Rooij for providing data from their studies on stoplight parrotfish in Bonaire.
\end{abstract}

\section{LITERATURE CITED}

Alonzo, S. H., T. Ish, M. Key, A. D. Maccall, and M. Mangel. 2008. The importance of incorporating protogynous sex change into stock assessments. Bulletin of Marine Science 83(1):163-179.

Alonzo, S. H., and M. Mangel. 2004a. The effects of size-selective fisheries on the stock dynamics of and sperm limitation in sexchanging fish. Fishery Bulletin 102(1):1-13.

Alonzo, S. H., and M. Mangel. 2004b. Sex-change rules, stock dynamics, and the performance of spawning-per-recruit measures in protogynous stocks. Fishery Bulletin 103(2):229-245.

Barlow, G. W. 1975. On the sociobiology of four Puerto Rican parrotfishes (Scaridae). Marine Biology 33:281-293. https://doi. org/10.1007/BF00390566

Bellwood, D. R., T. P. Hughes, C. Folke, and M. Nyström. 2004. Confronting the coral reef crisis. Nature 429:827-833. https://doi. org/10.1038/nature02691

Bozec, Y.-M., S. O’Farrell, J. H. Bruggemann, B. E. Luckhurst, and P. J. Mumby. 2016. Tradeoffs between fisheries harvest and the resilience of coral reefs. Proceedings of the National Academy of Sciences of the United States of America 113(16):4536-4541. https://doi.org/10.1073/pnas.1601529113

Chapin, I., F. S., G. P. Kofinas, and C. Folke. 2009. Principles of ecosystem stewardship: resilience-based natural resource management in a changing world. Springer, New York, New York, USA.

Choat, J. H., D. R. Robertson, J. L. Ackerman, and J. M. Posada. 2003. An age-based demographic analysis of the Caribbean stoplight parrotfish Sparisoma viride. Marine Ecology Progress Series 246:265-277. https://doi.org/10.3354/meps246265

Cinner, J. E. 2011. Social-ecological traps in reef fisheries. Global Environmental Change 21(3):835-839. https://doi.org/10.1016/j. gloenvcha.2011.04.012
Cinner, J. 2014. Coral reef livelihoods. Current Opinion in Environmental Sustainability 7:65-71. https://doi.org/10.1016/j. cosust.2013.11.025

Dulvy, N. K., R. P. Freckleton, and N. V. C. Polunin. 2004. Coral reef cascades and the indirect effects of predator removal by exploitation. Ecology Letters 7(5):410-416. https://doi.org/10.1111/ j.1461-0248.2004.00593.x

Froese, R., and D. Pauly. 2017.FishBase. Quantitative Aquatics Inc., Bay, Laguna, Philippines. [online] URL: https://www. fishbase.org

Graham, N. A. J., N. K. Dulvy, S. Jennings, and N. V. C. Polunin. 2005. Size-spectra as indicators of the effects of fishing on coral reef fish assemblages. Coral Reefs 24(1):118-124. https://doi. org/10.1007/s00338-004-0466-y

Green, A. L., A. P. Maypa, G. R. Almany, K. L. Rhodes, R. Weeks, R. A. Abesamis, M. G. Gleason, P. J. Mumby, and A. T. White. 2015. Larval dispersal and movement patterns of coral reef fishes, and implications for marine reserve network design. Biological Reviews 90:1215-1247. https://doi.org/10.1111/brv.12155

Grimm, V., U. Berger, D. L. DeAngelis, J. G. Polhill, J. Giske, and S. F. Railsback. 2010. The ODD protocol: a review and first update. Ecological Modelling 221(23):2760-2768. https://doi. org/10.1016/j.ecolmodel.2010.08.019

Grimm, V., E. Revilla, U. Berger, F. Jeltsch, W. M. Mooij, S. F. Railsback, H.-H. Thulke, J. Weiner, T. Wiegand, and D. L. DeAngelis. 2005. Pattern-oriented modeling of agent-based complex systems: lessons from ecology. Science 310 (5750):987-991. https://doi.org/10.1126/science.1116681

Haddon, M. 2011. Modelling and quantitative methods in fisheries. Second edition. Chapman and Hall, Boca Raton, Florida, USA.

Hawkins, J. P., and C. M. Roberts. 2004. Effects of fishing on sexchanging Caribbean parrotfishes. Biological Conservation 115 (2):213-226. https://doi.org/10.1016/S0006-3207(03)00119-8

Heppell, S. S., S. A. Heppell, F. C. Coleman, and C. C. Koenig. 2006. Models to compare management options for a protogynous fish. Ecological Applications 16(1):238-249. https://doi. org/10.1890/04-1113

Hughes, T. P. 1994. Catastrophes, phase shifts, and large-scale degradation of a Caribbean coral reef. Science 265 (5178):1547-1551. https://doi.org/10.1126/science.265.5178.1547

Hughes, T. P., N. A. J. Graham, J. B. C. Jackson, P. J. Mumby, and R. S. Steneck. 2010. Rising to the challenge of sustaining coral reef resilience. Trends in Ecology \& Evolution 25(11):633-642. https://doi.org/10.1016/j.tree.2010.07.011

Jackson, J. B. C., M. Donovan, K. Cramer, and V. Lam. 2012. Status and trends of Caribbean coral reefs: 1970-2012. Gland, Switzerland.

Kellner, J. B., S. Y. Litvin, A. Hastings, F. Micheli, and P. J. Mumby. 2010. Disentangling trophic interactions inside a Caribbean marine reserve. Ecological Applications 20 (7):1979-1992. https://doi.org/10.1890/09-1217.1 
Koltes, K. H. 1993. Aspects of the reproductive biology and social structure of the stoplight parrotfish, Sparisoma viride, at Grand Turk, Turks and Caicos Islands, B.W.I. Bulletin of Marine Science 52(2):792-805.

Lang, J. C., K. W. Marks, P. A. Kramer, P. R. Kramer, and R. N. Ginsburg. 2010. AGRRA protocols version 5.4. Ocean Research and Education Foundation, Big Pine Key, Florida, USA.

Madin, E. M. P., S. D. Gaines, J. S. Madin, and R. R. Warner. 2010. Fishing indirectly structures macroalgal assemblages by altering herbivore behavior. American Naturalist 176(6):785-801. https://doi.org/10.1086/657039

Mardle, S., and S. Pascoe. 2002. Modelling the effects of tradeoffs between long and short-term objectives in fisheries management. Journal of Environmental Management 65(1):49-62. https://doi.org/10.1006/jema.2001.0518

McClanahan, T. R., S. D. Donner, J. A. Maynard, M. A. MacNeil, N. A. J. Graham, J. Maina, A. C. Baker, J. B. Alemu I, M. Beger, S. J. Campbell, E. S. Darling, C. M. Eakin, S. F. Heron, S. D. Jupiter, C. J. Lundquist, E. McLeod, P. J. Mumby, M. J. Paddack, E. R. Selig, and R. van Woesik. 2012. Prioritizing key resilience indicators to support coral reef management in a changing climate. PLoS ONE 7(8):e42884. https://doi.org/10.1371/journal. pone. 0042884

McClanahan, T. R., N. A. J. Graham, J. Maina, P. Chabanet, J. H. Bruggemann, and N. V. C. Polunin. 2007. Influence of instantaneous variation on estimates of coral reef fish populations and communities. Marine Ecology Progress Series 340:221-234. https://doi.org/10.3354/meps340221

Ministerio de Medio Ambiente y Recursos Naturales. 2017. Medio Ambiente apuesta por la proteccion de especies marinas. Mediante la Resolución No. 023/2017. Ministerio de Medio Ambiente y Recursos Naturales, Santo Domingo, Dominican Republic.

Moberg, F., and C. Folke. 1999. Ecological goods and services of coral reef ecosystems. Ecological Economics 29(2):215-233. https://doi.org/10.1016/S0921-8009(99)00009-9

Mumby, P. J. 2006. The impact of exploiting grazers (Scaridae) on the dynamics of Caribbean coral reefs. Ecological Applications 16(2):747-769. https://doi.org/10.1890/1051-0761(2006)016[0747: TIOEGS]2.0.CO;2

Mumby, P. J., J. D. Hedley, K. Zychaluk, A. R. Harborne, and P. G. Blackwell. 2006. Revisiting the catastrophic die-off of the urchin Diadema antillarum on Caribbean coral reefs: fresh insights on resilience from a simulation model. Ecological Modelling 196(1-2):131-148. https://doi.org/10.1016/j. ecolmodel.2005.11.035

Munday, P. L., P. M. Buston, and R. R. Warner. 2006. Diversity and flexibility of sex-change strategies in animals. Trends in Ecology \& Evolution 21(2):89-95. https://doi.org/10.1016/j. tree.2005.10.020

Nadon, M. O., J. S. Ault, I. D. Williams, S. G. Smith, and G. T. DiNardo. 2015. Length-based assessment of coral reef fish populations in the main and northwestern Hawaiian Islands. PLoS ONE 10(8):e0133960. https://doi.org/10.1371/journal. pone. 0133960
Nyström, M., N. A. J. Graham, J. Lokrantz, and A. V. Norström. 2008. Capturing the cornerstones of coral reef resilience: linking theory to practice. Coral Reefs 27(4):795-809. https://doi. org/10.1007/s00338-008-0426-Z

O'Farrell, S., B. E. Luckhurst, S. J. Box, and P. J. Mumby. 2016. Parrotfish sex ratios recover rapidly in Bermuda following a fishing ban. Coral Reefs 35(2):421-425. https://doi.org/10.1007/ $\underline{\mathrm{s} 00338-015-1389-5}$

O'Farrell, S., R. Salguero-Gómez, J. M. van Rooij, and P. J. Mumby. 2015. Disentangling trait-based mortality in species with decoupled size and age. Journal of Animal Ecology 84 (5):1446-1456. https://doi.org/10.1111/1365-2656.12399

Ostrom, E. 2007. A diagnostic approach for going beyond panaceas. Proceedings of the National Academy of Sciences of the United States of America 104(39):15181-15187. https://doi. org/10.1073/pnas.0702288104

Paddack, M. J., S. Sponaugle, and R. K. Cowen. 2009. Smallscale demographic variation in the stoplight parrotfish Sparisoma viride. Journal of Fish Biology 75(10):2509-2526. https://doi. org/10.1111/j.1095-8649.2009.02451.x

Pavlowich, T., and A. R. Kapuscinski. 2017. Understanding spearfishing in a coral reef fishery: fishers' opportunities, constraints, and decision-making. PLOS ONE 12(7):e0181617. https://doi.org/10.1371/journal.pone.0181617

Pavlowich, T., D. G. Webster, and A. R. Kapuscinski. 2018. Leveraging sex change in parrotfish to managed fished populations. Elementa: Science of the Anthropocene 6(1):63. https://doi.org/10.1525/elementa.318

Restrepo, V. R., G. G. Thompson, P. M. Mace, W. L. Gabriel, L. L. Low, A. D. MacCall, R. D. Methot, J. E. Powers, B. L. Taylor, P. R. Wade, and J. F. Witzig. 1998. Technical guidance on the use of precautionary approaches to implementing National Standard 1 of the Magnuson-Stevens Fishery Conservation and Management Act. NOAA Technical Memorandum NMFS-F/SPO-31. U.S. Department of Commerce, National Oceanic and Atmospheric Administration, National Marine Fisheries Service, Silver Spring, Maryland, USA.

Robertson, D. R., and R. R. Warner. 1978. Sexual patterns in the labroid fishes of the western Caribbean, II: the parrotfishes (Scaridae). Smithsonian Contributions to Zoology 255. Smithsonian Institution Press, Washington, D.C., USA. https:// doi.org/10.5479/si.00810282.255

Rogers, A., A. R. Harborne, C. J. Brown, Y.-M. Bozec, C. Castro, I. Chollett, K. Hock, C. A. Knowland, A. Marshell, J. C. Ortiz, T. Razak, G. Roff, J. Samper-Villarreal, M. I. Saunders, N. H. Wolff, and P. J. Mumby. 2015. Anticipative management for coral reef ecosystem services in the 21st century. Global Change Biology 21(2):504-514. https://doi.org/10.1111/gcb.12725

Sabetian, A. 2010. Parrotfish fisheries and population dynamics: a case-study from Solomon Islands. Dissertation. James Cook University, Townsville, Queensland, Australia.

Salas, S. and D. Gaertner. 2004. The behavioural dynamics of fishers: management implications. Fish and Fisheries 5 (2):153-167. https://doi.org/10.1111/j.1467-2979.2004.00146.x 
Schultz, E. T., and R. K. Cowen. 1994. Recruitment of coral-reef fishes to Bermuda: local retention or long-distance transport? Marine Ecology Progress Series 109:15-28.

Sponaugle, S., K. Grorud-Colvert, and D. Pinkard. 2006. Temperature-mediated variation in early life history traits and recruitment success of the coral reef fish Thalassoma bifasciatum in the Florida Keys. Marine Ecology Progress Series 308:1-15.

Tolimieri, N. 1998. The relationship among microhabitat characteristics, recruitment and adult abundance in the stoplight parrotfish, Sparisoma viride, at three spatial scales. Bulletin of Marine Science 62(1):253-268.

van Rooij, J. M., J. P. Kok, and J. J. Videler. 1996a. Local variability in population structure and density of the protogynous herbivore Sparisoma viride. Environmental Biology of Fishes 47:65-80. https://doi.org/10.1007/BF00002380

van Rooij, J. M., F. J. Kroon, and J. J. Videler. 1996b. The social and mating system of the herbivorous reef fish Sparisoma viride: one-male versus multi-male groups. Environmental Biology of Fishes 47:353-378. https://doi.org/10.1007/BF00005050

Weijerman, M., E. A. Fulton, A. B. G. Janssen, J. J. Kuiper, R. Leemans, B. J. Robson, I. A. van de Leemput, and W. M. Mooij. 2015. How models can support ecosystem-based management of coral reefs. Progress in Oceanography 138B:559-570. https://doi. org/10.1016/j.pocean.2014.12.017

Wilson, M., T. Pavlowich, and M. Cox. 2016. Studying commonpool resources over time: a longitudinal case study of the Buen Hombre fishery in the Dominican Republic. Ambio 45 (2):215-229. https://doi.org/10.1007/s13280-015-0688-y 